\title{
Chapter 31
}

\section{Nanoparticles for Hyperthermia Applications}

\author{
Tomy J. Gutiérrez and Vera A. Alvarez \\ Thermoplastic Composite Materials (CoMP) Group, Institute of Research in Materials Science and Technology (INTEMA), Faculty of Engineering, \\ National University of Mar del Plata (UNMdP) and National Scientific and Technical Research Council (CONICET), Mar del Plata, Buenos Aires, \\ Argentina
}

\subsection{INTRODUCTION}

Hyperthermia is a method for the treatment of malignant tumors that artificially elevates target tissue temperatures. Hyperthermia using magnetic particles was first proposed in the 1950s by Gilchrist et al. [1] and is still under development today [2]. It has recently attracted considerable interest as a novel cancer treatment, as compared with radiotherapy and chemotherapy it causes virtually no side effects to other organs, as well as being relatively noninvasive [3]. The efficiency of this type of thermotherapy has been demonstrated for several types of cancers, including brain, prostate, and breast cancers [3].

Treatment by hyperthermia kills cancer cells in tumors by heat irradiation. The technique consists of targeting magnetic nanoparticles (MNPs) toward tumor tissue followed by the application of an external alternating magnetic field (AMF) that generates heat via two mechanisms: (1) hysteresis losses of the ferromagnetic particles; and/or (2) Néel and Brownian relaxation by superparamagnetic particles through targeting [4], which heats the tissue containing the MNPs (Fig. 31.1) $[2,5,6]$. The temperature in the tumor tissue increases to $41-46^{\circ} \mathrm{C}$ [7] causing the necrosis of the cancer cells (cell processes up to apoptosis), while leaving the surrounding healthy tissue undamaged. In addition to this direct effect, tumor-specific immune responses, including heat-shock protein expression, have been observed during in vivo and in vitro experiments, demonstrating the potential of this therapy to act not only locally, but also at distant sites including metastatic cancer cells [8].

Two types of heating treatments are currently performed: (1) hyperthermia at $41-46^{\circ} \mathrm{C}$ which stimulates the immune response for nonspecific immunotherapy; and (2) thermoablation at $46-56^{\circ} \mathrm{C}$, aimed at initiating cell necrosis, coagulation, or carbonization for tumor destruction $[3,9]$.
The characteristic temperature of tumor cell thermoablation is very close to that of normal cells, making temperature control unnecessary. MNPs can act as nanoscale mediators converting electromagnetic energy into heat when exposed to an external electrical or magnetic field after injection as the particles are dispersed. However, inductive hyperthermia (with MNPs) seems currently more useful, as body tissue susceptibility is very low and does not constitute a heat source in a magnetic field [10].

Nevertheless as a rule, MNPs are toxic for living organisms. This means that the magnetic particles must be coated with, or encapsulated into, biocompatible materials during or after synthesis in order to prevent (1) changes to their initial state, (2) the formation of large aggregates, and (3) biodegradation due to interactions with the biological system.

For in vivo biomedical applications, the MNPs employed must be nontoxic, nonimmunogenic, and small enough to pass through the capillary systems of organs and tissues, thus remaining in circulation after injection and avoiding the embolism of blood vessels. They should also have a high level of magnetization so that their motion in the blood can be controlled by varying the magnetic field, thus enabling them to be delivered to the site of the diseased tissue [11].

In this context, composite materials from iron oxide/ biomaterials or iron oxide/hydroxyapatite (HA) are typically used for hyperthermia treatment [12], although nickel and cobalt oxide composites also have appropriate ferromagnetic properties for hyperthermia applications at physiological temperature [13].

Iron oxides, such as magnetite $\left(\mathrm{Fe}_{3} \mathrm{O}_{4}\right)$ or $\gamma$-hematite $\left(\gamma-\mathrm{Fe}_{2} \mathrm{O}_{3}\right)$, are commonly used as thermoseeds for hyperthermia due to their biodegradable nature, biocompatibility, and superparamagnetic effects, i.e., they generate heat 


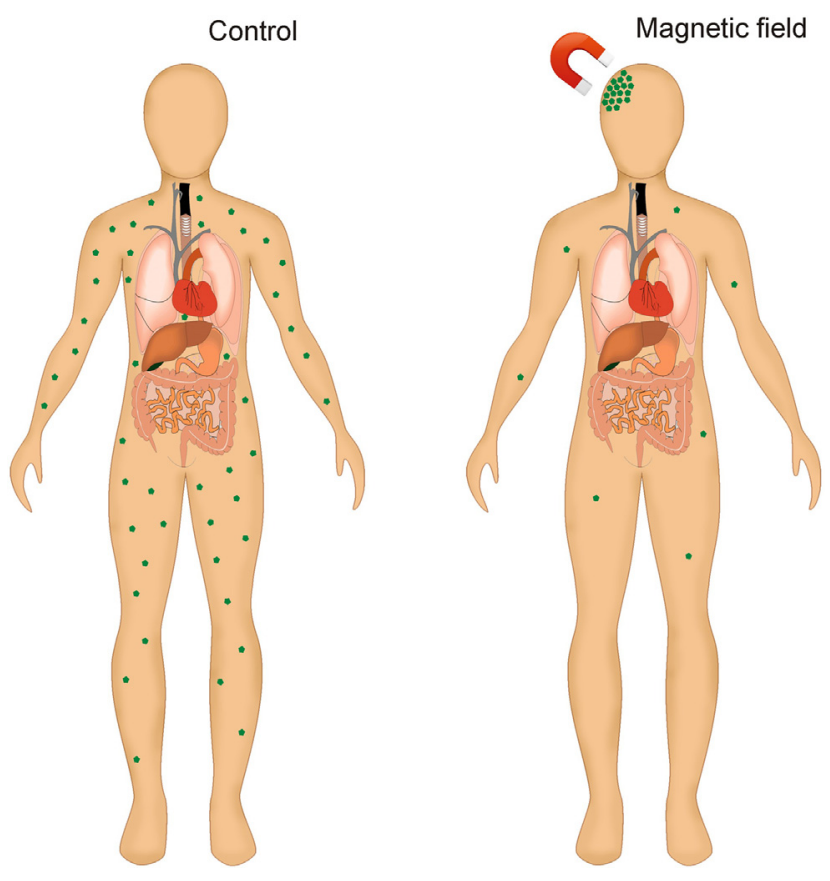

FIGURE 31.1 Magnetic targeting. No accumulation of MNPs occurs in the absence of a magnetic field, whereas under the influence of this field, MNPs alone or in combination with therapeutic cargo accumulate at a destined site. This includes the brain. Targeting efficiency of MNPs can be further improved by modifying the MNP surface using cellspecific targeting moieties, for instance, transferrin for brain targeting. $M N P s$, magnetic nanoparticles.

when subjected to alternate magnetic fields [14-17]. $\mathrm{Fe}_{3} \mathrm{O}_{4}$ is widespread in the environment, despite the fact that it is less thermodynamically stable than $\gamma-\mathrm{Fe}_{2} \mathrm{O}_{3}$ in the presence of oxygen [18]. The long-term instability of the properties of MNPs has led researchers to study $\gamma-\mathrm{Fe}_{2} \mathrm{O}_{3}$. The disadvantage of the slightly lower bulk saturation magnetization of this iron oxide $[19,20]$ is compensated by its greater stability.

Nonetheless, $\mathrm{Fe}_{3} \mathrm{O}_{4}$ microspheres have also been developed [21-23], since they exhibit an embolization effect by blocking the blood vessels near the tumors and consequently shutting off the supply of nutrients to the cancer cells.

Iron oxide particles are used at a nanoscale (iron nanoparticles-INPs) for hyperthermia applications, and it has been observed that many of the particular properties of INPs with diameters between 6 and $30 \mathrm{~nm}$ can be modified, e.g., their superparamagnetism properties can be improved and the saturation field (the external field needed for saturation magnetization) raised [24-26].

INPs usually exhibit superparamagnetic behavior, due to their small volume, meaning that their thermal energy may be enough to spontaneously change the degree of magnetization within each INP. In other words, the magnetic moment of each INP is able to rotate randomly (relative to the orientation of the INP) simply because of its temperature. For this reason, in the absence of an electromagnetic field, the net magnetic moment of a system containing INPs will be zero at high enough temperatures [27].

However, in the presence of a field, there will be a net statistical alignment of magnetic moments, analogous to what happens to paramagnetic materials, except that now the magnetic moment is not that of a single atom, but of MNPs containing various atoms, making each moment up to $10^{4}$ times larger than for a paramagnetic material [27].

The properties described above enable the real-time in vivo monitoring of MNP distribution [28,29]. Nonetheless, the nanosized magnetite particles tend to aggregate because of their high specific area and strong interparticle interactions, which limits their use [30]. Thus, in order to ensure stability and nontoxicity under physiological conditions, as well as to allow for functionalization and targeting, these materials must be coated or encapsulated. These coatings or encapsulants should ideally have a high affinity for the iron oxide core, be nonimmunogenic and nonantigenic, and prevent opsonization by plasma proteins [31]. Materials used as coatings or encapsulants include liposomes, lipids, dendrimers, proteins, polyethylene glycol, polysaccharides, polyacrylamide, bisphosphonates, silicon dioxide [32], noble metals ( $\mathrm{Au}$ and $\mathrm{Ag}$ ) [33], and titanium dioxide [31], resulting in the development of composite materials composed of INPs and biopolymers.

In addition, the poor solubility and stability in water of INPs at physiological pH may be prevented by coating them with a water-soluble polymer [34,35]. For example, biocompatible polymers have been used as coatings, since they can be bound to drugs, antibodies, enzymes, proteins, or nucleotides, and can be directed to an organ, tissue, or tumor using an external magnetic field. However, some studies have shown that a nonpolar coating made from fatty acids could improve the antitumor properties of MNPs [36].

\subsection{SYNTHESIS OF IRON NANOPARTICLES (INPS)}

The performance of INPs is dependent on the chemical and physical characteristics of MNPs and their surfaces, which are themselves greatly influenced by the method of synthesis chosen for their preparation [37]. The control of particle size, shape, distribution, crystallinity, and colloidal and magnetic properties, such as saturation magnetization and susceptibility, is crucial. The method of synthesis must then permit the tailoring of the size and surface chemistry of the MNPs in order to meet specific demands for physical and biological applications [37]. 
INPs may be synthesized by various methods such as coprecipitation, hydrothermal, laser pyrolysis, sol-gel, and biopolymer-inducing procedures, or sonochemical synthesis [24,38-45]. The first two of these methods are the ones most commonly used.

\subsubsection{Coprecipitation}

The most efficient and easiest method is to coprecipitate the magnetite using soluble salts in water (e.g., chloride, nitrate) $[41,43]$ using one of two procedures:

1. The controlled oxidation of an $\mathrm{Fe}^{2+}$ aqueous solution in an alkaline medium, to produce $\mathrm{Fe}^{2+}$ and $\mathrm{Fe}^{3+}$ at a molar ratio of 1:2 [40]. In this case, because controlled oxidation of $\mathrm{Fe}^{2+}$ is very difficult to obtain, only $\mathrm{Fe}_{3} \mathrm{O}_{4}$ results;

2. The addition of a high $\mathrm{pH}$ (alkaline) solution to an aqueous mixture of $\mathrm{Fe}^{2+}$ and $\mathrm{Fe}^{3+}$ at a molar ratio of $1: 2[38,39,44,46-48]:$

$$
\mathrm{Fe}^{2+}+2 \mathrm{Fe}^{3+}+8 \mathrm{OH}^{-} \rightarrow \mathrm{Fe}_{3} \mathrm{O}_{4}+4 \mathrm{H}_{2} \mathrm{O}
$$

This reaction takes place at $\mathrm{pH}=9-14$, under a nonoxidizing, oxygen-free environment.

However, if oxygen is present, $\mathrm{Fe}_{3} \mathrm{O}_{4}$ is oxidized to $\mathrm{Fe}(\mathrm{OH})_{3}$ :

$$
\mathrm{Fe}_{3} \mathrm{O}_{4}+1 / 2 \mathrm{O}_{2}+4 \mathrm{H}_{2} \mathrm{O} \rightarrow 3 \mathrm{Fe}(\mathrm{OH})_{3}
$$

And under air conditions, $\mathrm{FeO}$ from $\mathrm{Fe}_{3} \mathrm{O}_{4}$ is oxidized forming a pure $\mathrm{Fe}_{2} \mathrm{O}_{3}$ phase:

$$
2\left(\mathrm{FeO} \cdot \mathrm{Fe}_{2} \mathrm{O}_{3}\right)+1 / 2 \mathrm{O}_{2} \rightarrow 3 \mathrm{Fe}_{2} \mathrm{O}_{3}
$$

Thus, under aerobic conditions pure magnetite is not obtained due to the oxidation process. To avoid this inconvenience the reaction can be conducted under an inert nitrogen $\left(\mathrm{N}_{2}\right)$ atmosphere $[49,50]$. Distilled water degassed with $\mathrm{N}_{2}$ can also be used for the preparation of an aqueous solution. After precipitation, the magnetite is calcinated under an $\mathrm{N}_{2}$ atmosphere.

By coprecipitating in a highly basic aqueous medium the magnetite nanoparticles (MNPs) acquire negative charges on their surfaces, preventing their agglomeration by repulsion phenomena. The negativity of the magnetite surfaces increases with the alkalinity of the aqueous medium.

This process, which involves the formation of intermediate hydroxyl species, is affected by experimental parameters such as temperature, $\mathrm{pH}$, the concentration of the cations, and the nature of the base, which greatly influence average MNP size in the range of $3-20 \mathrm{~nm}$. It is noteworthy that $\mathrm{pH}$ is a particularly critical parameter affecting both MNP size (an increase in the $\mathrm{pH}$ induces repulsion among primary MNPs giving smaller magnetite
MNPs) and their stable dispersion. In particular, thanks to electrostatic surface repulsion phenomena, stable ionic ferrofluids can be obtained over a wide $\mathrm{pH}$ range. The coprecipitation approach offers many advantages including: the use of cheap chemicals and mild reaction conditions; the possibility to directly synthesize the INPs in water; the ease of scale-up; and the production of highly concentrated ferrofluids due to the high density of surface hydroxyls. Most importantly, the synthetic route is extremely flexible when it comes to the modulation of core and surface properties. Conversion to maghemite is easily obtained by the chemical oxidation of the magnetite colloids, and substituted ferrites can be prepared by the alkalinization of aqueous mixtures of a ferric salt and a salt of a divalent metal under boiling conditions [51]. Likewise, thanks to the high density of reactive sites, surface modification can be easily performed by the direct incorporation of additives, which is particularly useful for large-scale production as is the case of the carbonate method [52]. A general limitation of the hydrolytic approach lies in the large number of parameters, which have to be carefully monitored in order to control the synthetic outcome, resulting from the complex aqueous chemistry and rich phase diagram of the iron oxide phases.

As a major drawback of hydrolytic routes lies in the limited control of MNP size distribution, synthesis in confined environments, such as microemulsions, has been proposed. In particular, reverse micelles have been used to carry out the classic coprecipitation reaction [53] and the hydrolysis of metal-surfactant complexes [54] in water-in-oil emulsions. The parameters that affect MNP size are: (1) the microstructure and composition of the microemulsion, including both the surfactant [most commonly sodium bis(2-ethylhexyl) sulfosuccinate (AOT), cetyl trimethylammonium bromide or dodecyl sulfonate (DS)], and the hydrocarbon that constitutes the continuous phase (such as hexane, heptane, octane); (2) the temperature; and (3) the type of counterion. Reverse micelles have been successfully employed as a means to mediate the formation of iron oxide MNPs, as well as substituted ferrites with an improved size distribution in the 4-12 nm range (typical size of the water-in-oil microemulsion droplets) [55-58].

In addition to improving the magnetic properties of the synthesized MNPs the coprecipitation method can be performed under hydrothermal conditions [53]. Hydrothermal routes have also been used for hydrolytic procedures starting from iron complexes, such as the ageing of iron polyolates in aqueous acidic/basic solutions, followed by digestion in autoclave at $80-150^{\circ} \mathrm{C}$ for several days [54]. In this approach reaction conditions, such as the solvent used, temperature, and time, generally significantly affect the synthetic outcome. The size of the 
crystallized MNPs is controlled mainly through the competing rate processes of nucleation and particle growth.

\subsubsection{Hydrothermal Method}

The hydrothermal method is used to obtain many fine metal oxide particles with various shapes and morphologies, which have a significant influence on their properties. This method uses a pressure higher than $1 \mathrm{~atm}$. coupled with a low synthesis temperature $\left(100-500^{\circ} \mathrm{C}\right)$ without subsequent heat treatments, and with different plateaus. Some of the advantages of this method are: no organic reagents are used; it is relatively cost-effective; a high particle crystallinity is achieved with the possibility of efficiently controlling the size and desired morphology of the resulting materials (e.g., nanorods, nanowires, nanotubes, nanobelts, necklace, and hollow nanospheres); good dispersion characteristics are obtained (e.g., monodispersion); high yields of the desired products are easily attained [59-65]. In addition, this method uses watersoluble salts, and the reaction generally takes place in an alkaline medium under an $\mathrm{N}_{2}$ atmosphere. Finally, an aqueous solution may be prepared using distilled water degassed with $\mathrm{N}_{2}$ (for 30 minutes or 1 hour) and surfactants or templates used for obtaining the mesoporous magnetite.

\subsection{MAGNETITE: TUMOR TREATMENT USING AN EXTERNAL MAGNETIC FIELD}

Metal-based nanoscale particles possess unique optoelectronic or magnetic properties that make them highly promising as imaging agents in cancer therapy research [66-72]. Inspired by physiologically existing nanomachines, NPs are designed to safely reach their target and release their cargo at the specific site of the disease, thus increasing tissue bioavailability of the drug employed. The site-specific delivery of therapeutics to tumors is accomplished through both active and passive mechanisms.

With their unique structural properties of high surface to volume ratio and hollow structure, nanomaterials can carry an extremely high drug payload $[15,73,74]$. Nanomaterials with specific optical or magnetic characteristics may also be regulated by radiation or magnetic fields for the controlled release of drug molecules $[75,76]$.

NPs are able to target cancer cells by simply being accumulated and entrapped in tumors (passive targeting). This phenomenon is called "the enhanced permeation and retention (EPR) effect," and is caused by leaky angiogenetic vessels and poor lymphatic drainage. The EPR effect has been used to explain why macromolecules and NPs are found at higher ratios in tumors compared to normal tissues [77]. The exploitation of this effect requires the careful selection of the size of the NPs, so that they extravasate leaky tumor vasculature but are themselves retained in the tumor due to insufficient lymphatic drainage [78]. NPs between 100 and $200 \mathrm{~nm}$ have been shown to accumulate in tumors by the EPR effect, and the retention of large molecules is typically higher than that of small molecules which can more easily diffuse back into the vasculature. As well as having an appropriate size, NPs must achieve an optimum concentration gradient over a sustained time period of at least 6 hours to allow for a long circulation time [76].

\subsection{IN VIVO STUDIES DEMONSTRATING THE ANTICANCER EFFECTS OF MAGNETIC NANOCARRIERS}

Kawai et al. [79] demonstrated, using a rat model, that hyperthermia employing magnetic cationic liposomes (MCLs) is an effective therapy for prostate cancer. MCL therapy acted either directly by killing rat prostate cancer cells in vivo after heating to $45^{\circ} \mathrm{C}$, or indirectly by inducing an immune response. MCLs have a positive surface charge and generate heat in an AMF due to hysteresis losses. Tumor regression and the presence of CD3, CD4, and CD8 immunocytes were observed in the hyperthermic group. HSP70 also appeared at the boundary between the viable and necrotic areas. Induction of antitumor immunity by intracellular hyperthermia using MCLs was also demonstrated for solid T-9 rat glioma tissues. Treated tumor tissue disappeared completely in many rats exposed to the AMF $(118 \mathrm{kHz}, 384 \mathrm{Oe})$, generated three times for 30 minutes each at 24-hour intervals. Untreated solid tumors on the opposite side also disappeared completely, even though MCLs were not injected into them. To examine whether a long-lasting, tumor-specific immunity could be generated, the rats cured by the hyperthermia treatment were rechallenged with T-9 cells 3 months later. After a period of transient growth, all the tumors disappeared. Immunocytochemical assays revealed that the immune response induced by the hyperthermia treatment was mediated by both $\mathrm{CD} 8^{+}$and $\mathrm{CD} 4^{+} \mathrm{T}$ cells accompanied by a marked augmentation of tumor-selective cytotoxic $\mathrm{T}$ lymphocyte activity. These results suggest that magnetic particles are potentially effective tools for the hyperthermic treatment of solid tumors, as in addition to killing the tumor cells by heating, a host immune response is induced [80].

Ito et al. [81] constructed anti-HER2 immuno-liposomes containing magnetite NPs, which act as tumor-targeting vehicles, thus combining anti-HER2 antibody therapy with hyperthermia. The magnetite NP-loaded anti-HER2 immuno-liposomes exerted HER2-mediated antiproliferative effects on $\mathrm{SKBr} 3$ breast cancer cells in vitro. Around $60 \%$ of the magnetite NPs were incorporated into the 
$\mathrm{SKBr} 3$, and the cells were then heated to $42.5^{\circ} \mathrm{C}$ under an AMF, resulting in strong cytotoxic effects. These results suggest that this novel therapeutic tool may be effectively used to treat HER2-overexpressing cancer [81].

In another study, dextran magnetite was incorporated into liposomes in order to obtain thermosensitive magneto-liposomes which proved to exhibit anti-tumoral effects on AH60C rat tumors, (the tumors were treated with $15 \mathrm{mg}$ iron $/ \mathrm{cm}^{3}$ and exposed to a $500 \mathrm{kHz}$ electromagnetic field generated by inductive heating). A temperature of $42^{\circ} \mathrm{C}$ was maintained for 7 minutes inside the tumor, without affecting the surrounding tissues. The tumor cells disappeared completely in the treated animals and survival rates were significantly higher than those of the control group [82].

\subsection{IN VITRO STUDIES DEMONSTRATING IMPROVEMENTS IN THE UPTAKE RATE OF ANTICANCER AGENTS LOADED ONTO NANOPARTICLES IN DIFFERENT TUMOR CELLS}

$\mathrm{Hu}$ et al. [83] synthesized tamoxifen-loaded magnetite/poly (L-lactic acid) composite nanoparticles (TMCN) with an average size of approximately $200 \mathrm{~nm}$, in order to study their in vitro anticancer activity against MCF-7 breast cancer cells. The superparamagnetic property (saturation magnetization value of approximately $7 \mathrm{emu} / \mathrm{g}$ ) of the TMCN was provided by $\mathrm{Fe}_{3} \mathrm{O}_{4} \mathrm{NPs}$ of approximately $6 \mathrm{~nm}$ encapsulated in the poly(L-lactic acid) matrix. The uptake rate of the TMCN and tamoxifen by the MCF-7 cells was estimated from the intracellular iron concentration. Significant changes in MCF-7 tumor cell morphology were discernible from phase contrast microscopy after only 4 hours incubation with the TMCN, and approximately $80 \%$ of cells were killed after 4 days incubation [83].

Temperature-sensitive poly $(N$-isopropylacrylamideacrylamideallylamine)-coated iron oxide magnetic nanoparticles (TPMNPs), prepared by the free radical polymerization of monomers on the surface of silanecoupled INPs, were cytocompatible and effectively taken up by advanced thyroid cancer (ATC) cells in a dosedependent manner. An external magnetic field significantly increased NP uptake, especially when the cells were exposed to physiological flow conditions. Drug loading and release studies using doxorubicin confirmed the temperature-responsive release of the drugs from the NPs. In addition, the doxorubicin-loaded NPs killed significantly more ATC cells compared to free doxorubicin. These in vitro results indicate that TPMNPs have potential as carriers for the controlled and targeted delivery of drugs for thyroid cancer treatment [84].
In another study, Sun and Liang [85] compared the antitumor activity of cisplatin or cis-diaminodichloroplatin (CDDP)-loaded liposomes with NPs in vitro. These authors demonstrated that nanocarriers with similar pharmaceutical parameters can induce differences in cellular internalization and elimination, which eventually influence antitumor activity. Compared to gelatin NPs, liposome is preferable for cisplatin delivery [85].

Currently, most research is focused on the design and engineering of new scalable and economically viable multifunctional (multiplex) systems, capable of: identifying malignant cells by molecular detection; visualizing their location in the body using contrast-enhanced medical imaging techniques; killing diseased cells with minimal side effects through selective drug targeting and monitoring treatment in real time [86]. The in vivo fate and functions of NPs ultimately depend on their interactions with blood proteins, and in this context coating the NPs strongly influences their cellular uptake rate.

\subsection{SATURATED FATTY ACIDS AS COATINGS FOR MAGNETIC NANOPARTICLES WITH IMPROVED ANTICANCER DRUG CARRIER PROPERTIES}

Saturated fatty acids (SFAs) account for $30 \%-40 \%$ of the total amount of Fatty acids (FAs) in animal tissues and are distributed in palmitic acid $(15 \%-25 \%)$, stearic acid $(10 \%-20 \%)$, myristic acid $(0.5 \%-1 \%)$, and lauric acid (less than $0.5 \%$ ). Palmitic and stearic acids are universally found in natural fats $[87,88]$, whilst lauric acid is specifically abundant in copra $(39 \%-54 \%)$ and palmist oils (44\%-51\%). Myristic acid and short-chain fatty acids (including butyric acid) represent about $10 \%$ each of the FAs in milk fat. The body is also capable of synthesizing SFAs. The SFAs C12:0 to C18:0 can be converted to their respective monounsaturated analogues by the action of $\Delta$ 9-desaturase (stearoyl-CoA desaturase-SCD). Myristic and palmitic acids are involved in the fatty acid acylation of proteins, which involves N-terminal myristoylation to the $\mathrm{NH}_{2}$-terminal glycine, and side-chain palmitoylation by the posttranslational formation of a thioester linkage between the side-chains of cysteine and palmitic acid $[89,90]$.

Myristoylation induces protein activation, the myristoyl moiety being involved in the mediation of protein subcellular localization, protein-protein interactions, or protein-membrane interactions. About $0.5 \%$ of human proteins (structural proteins, components of intracellular signaling pathways, oncogenes, partially caspasedegraded actin, gelsolin, protein kinases) [91-94], but also viral proteins, can be myristoylated [95]. 
The association of proteins with the palmitoyl moiety is reversible and facilitates protein-membrane interactions and the subcellular trafficking of proteins (e.g., the $\alpha$ subunit of many heterotrimeric G proteins) [96]. SFAs (C10:0-C18:0) can also elevate or activate transcription factors (PGC-1 $\beta$, SREBP family), consequently increasing the transcription of lipogenic target genes (FAS, SCD-1). Coactivation of the nuclear receptor LXR/RXR may promote VLDL secretion. Palmitate induced the recruitment of several transcription factors, such as NF- $\kappa B$, hepatocyte nuclear factor 4 (HNF4), CEBP $\alpha$, and PPAR $\alpha$ [97]. SFAs (but also monounsaturated FAs) are known to bind HNF4. In liver cells, palmitate and oleate have been shown to inhibit the transcription of the glucose-6phosphatase gene [98].

SFAs, either free or linked to the lipid A moiety of

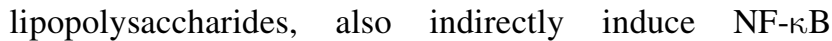
nuclear translocation, activation, and expression of COX2 and other pro-inflammatory cytokines, through the recently described toll-like receptor 4-derived signaling pathways [99]. Butyric acid is an inhibitor of histone deacetylase activity, with consequences for the structure of chromatin [100]. The inhibition of histone deacetylase can stimulate cellular differentiation, arrest growth, and promote apoptosis in a variety of cancer cells [101] by different mechanisms, for example, NF- $\kappa$ B activation, by affecting histone activity, or ceramide de novo synthesis [102-104]. A recent study showed that fatty acid biosynthesis and fatty acid desaturation was profoundly modified during the senescence process in cultured human fibroblasts [105].

It is commonly recognized that SFAs play a role in debilitating age-related illnesses such as type-2 diabetes and coronary heart disease. Elevated concentrations of palmitic acid are toxic to mitochondria and endoplasmic reticulum and can induce apoptosis without the involvement of reactive oxygen species. Changes in fatty acid composition with aging are consistent with a reduction in the activity of the stearoyl-CoA-desaturase 1 (SCD1) gene and consequent increases in the concentrations of palmitic and stearic acids relative to palmitoleic and oleic acids. The reduced activity of SCD1 is an outcome of p53 activation and has an ongoing effect on mitochondrial and cell functions [106]. Stearic acid has been proved to have a neutral effect on cholesterol, but could be pro-lipogenic thus acting as a stimulating factor for VLDL-TAG $[107,108]$. Studies on rats have shown that lauric acid could be a precursor for $\omega 3$ fatty acid biosynthesis, for example, $\alpha$-linolenic acid, by successive $\Delta 6$-desaturation, elongation, $\Delta 5$-desaturation, and two final elongations [109].

Thermally stable poly[aniline-co-sodium $\mathrm{N}$-(1-onebutyric acid) aniline]-coated $\mathrm{Fe}_{3} \mathrm{O}_{4}$ MNPs, employed as praclitaxel (PTX) carriers, were more stable at $37^{\circ} \mathrm{C}$ than free PTX (57-hour vs 19-hour at $37^{\circ} \mathrm{C}$ ). The PTX carriers also showed a longer circulation time and lower $\mathrm{IC}_{50}$ than free PTX in human prostate carcinoma cells: PC3 and CWR22R, respectively. The application of a magnetic field resulted in an even lower $\mathrm{IC}_{50}$ [110].

Oleic acid-coated and pluronic-stabilized MNPs produced an increase in circulation time in mice, and when doxorubicin and PTX were incorporated into these MNPs, synergistic antiproliferative effects were observed [111].

NPs incorporating palmitoyl ascorbate have been proved to enhance the antitumor activity of ascorbate, which at high doses acts as a prooxidant in tissue fluids and delivers peroxide to tissues and fluids. The peroxide is then detoxified by erythrocytes and plasma catalase in normally perfused areas, but can kill cancer cells under in vitro conditions [112].

\subsection{THE FABRICATION AND CHARACTERIZATION OF MAGNETITE COATED WITH A NONPOLAR SHELL WITHOUT USING AN EXTERNAL MAGNETIC FIELD, AND IN VITRO ASSAYS OF ITS ANTITUMOR ACTIVITY}

It is well known that free ferrous iron $\left(\mathrm{Fe}^{2+}\right)$ can participate in the Fenton reaction, producing the highly toxic hydroxyl radical $(\bullet \mathrm{OH})$. This could favor the appearance of malignant cells by inducing DNA lesions [113]. On the other hand, cancer cells are generally deficient in the antioxidant enzymes present in normal cells [114] making them vulnerable to iron-mediated oxidative assaults. Thus, iron overload in tumor cells could constitute a successful therapeutic approach for the treatment of cancer [115]. A few studies have shown that the passive accumulation of INPs in tumor cells could have an antitumor effect. For example, the injection of NPs containing the equivalent of total iron body stores into athymic nude mice bearing MCF-7 xenograft tumors decreased tumor size and increased the animal's survival [115]. While MNPs passively localize tumors through the enhanced permeability and retention effect, targeted formulations may further increase the effectiveness of the proposed therapy. The local delivery of iron-oxide through targeting by a magnetic field or by applying an adequate coating should thus be explored.

Fatty acids have been used in the design of solid lipid NPs: a class of particulate drug carriers that remain in a solid state at both room and body temperatures. Solid lipid NPs have the advantage of combining physical stability with low toxicity and are increasingly used for the protection of labile drugs from degradation in the body, 
and for their controlled and sustained release [116,117]. The application of lipid-based formulations for anticancer drug delivery has overcome many obstacles commonly found in conventional cancer chemotherapy, such as limited specificity, high toxicity, and the tendency to generate drug resistance $[118,119]$.

\subsection{BIOCOMPOSITES FROM IRON NANOPARTICLES-BIOPOLYMERS}

For biomedical applications, iron oxide MNPs must be precoated with substances that assure their stability, biodegradability, and nontoxicity in physiological media in order to achieve the combined properties of high magnetic saturation, biocompatibility, and interactive surface functions [120]. The size and surface properties of iron oxide NPs can dramatically affect NP stability and efficiency. MNPs should ideally be superparamagnetic and possess high magnetization properties. This means that their movements in the blood can be controlled with an external magnetic field, and that they can be immobilized close to the target tissue [121]. Surfactants are used to coat MNPs since they act as a steric barrier thus preventing aggregation caused by magnetic dipole-dipole attractions between particles and avoiding opsonization [122]. In this context, polymeric coatings provide a means to tailor the surface properties of MNPs such as surface charge and chemical functionality [123]. The iron oxide core can be coated with polymers during the synthesis process, which must be long-chain.

A few studies have been undertaken in which MNPs were coated with a biocompatible shell [124], or embedded in a polymer [125] to avoid aggregation and confer biocompatibility [126]. Recently, Soleymani et al. [127] reported that polymer-coated $\mathrm{La}_{0.73} \mathrm{Sr}_{0.27} \mathrm{MnO}_{3} \quad \mathrm{NPs}$ may have potential applications in cancer hyperthermia therapy and magnetically activated drug delivery. Nevertheless, current magnetic drug delivery systems still need to overcome some challenges including the unacceptable coincidental heating of healthy tissue, difficulties encountered in controlling drug release time and the released amount, and cytotoxicity and biocompatibility issues. More extensive work in this direction is thus required.

According to some reports [128], particles in the range of $10-100 \mathrm{~nm}$ appear to be ideal for biomedical use as they are small enough to penetrate very narrow capillaries within body tissues. This leads to a more effective distribution, ensuring adequate blood circulation times. Biswas et al. [129] investigated the loading and release capacity of a test antibiotic, ciprofloxacin, in a grown polymer embedded with $\mathrm{La}_{0.67} \mathrm{Sr}_{0.33} \mathrm{MnO}_{3}$ (LSMO) NPs, and its effects on different microorganisms. The controlled release profile of the loaded drug in distilled water was investigated as a function of time as reported in Gupta and Bajpai [130]. DC magnetization assays showed that the grown polymer embedded with LSMO exhibited magnetic behavior similar to that of LSMO alone without producing any significant changes to the Curie temperature $\left(T_{C}\right)$. The hysteresis behavior of the parent sample was also preserved with almost the same coercive field value, but with a lower magnetic moment. The drug loading and release experiments showed that after $8 \mathrm{~h}, \gg 90 \%$ of the ciprofloxacin loaded in the grown LSMO-embedded polymer was released. The minimum inhibitory concentrations of the loaded ciprofloxacin were studied for selected species of Gram-positive and Gram-negative bacteria. Good antibacterial activity was found against a Gram-positive bacteria, Bacillus subtilis and a Gram-negative bacteria, Salmonella typhi. These results are encouraging as the antibacterial activity was comparable to that of free ciprofloxacin for at least some of the bacterial strains. This means that these particles may be used for magnetically activated drug delivery whereby the drugs carried may be released on reaching the intended diseased site in the body. It must be mentioned that the focus of this study was on drug loading and release. Obviously, other issues, such as minimizing the side effects of the drug at the target site, need to be addressed.

Among the coating materials studied to date, chitosan (CS) is one of the most promising. CS prevents particles reacting with blood proteins and receptors [131]. Aziz et al. [132] synthesized magnetic INPs by the coprecipitation method, due to its potential for large-scale manufacturing, cost-effectiveness, ease of production, and the hydrophilicity of the nanocrystals [133].

For biomedical applications, CS-coated MNPs are generally synthesized by the in situ coating method, i.e., the alkaline coprecipitation of $\mathrm{Fe}^{2+}$ and $\mathrm{Fe}^{3+}$ precursors in aqueous solutions of hydrophilic CS polymers. The polymers limit the core growth of iron oxide during the preparation, and stabilize, via steric repulsions, the dispersed NPs in the aqueous media [10]. The coprecipitation method involves the precipitation of iron salts in the presence of CS and trisodium phosphate, which crosslinks the adsorbed CS molecules to each other through an ionic interaction.

Aziz et al. [132] evaluated the effectiveness of magnetic CS-coated INPs for biomedical applications. The prepared biocomposite was characterized using several analyses for comparative study. The coprecipitation method used by these authors has some advantages over previously published methods [134] as the process is simple and can be performed under mild conditions without using hazardous organic solvents. The authors hypothesized that the ionically cross-linked CS NPs would be more biocompatible than the covalently 
cross-linked CS NPs [135,136]. The X-ray diffraction (XRD) patterns revealed that the iron oxide NPs had a crystalline structure, whereas the CS coating gave a noisy amorphous peak indicative of a noncrystalline material [137]. Crystallite size as measured from X-ray powder diffraction was about $13.4 \mathrm{~nm}$, confirming its usefulness for biomedical applications. Scanning electron microscopy (SEM) images of the CS-coated MNPs showed that the particles were spherical. The FTIR spectra confirmed the presence of metal-oxygen bonding.

Lyubutin et al. [138] developed hollow microcapsules from biodegradable polyelectrolytes, poly-L-lysine (PLL) and dextran sulfate (DS). The microcapsules were constructed using the layer-by-layer adsorption technique. The capsule shells (PLL/DS) ${ }_{4}$ were modified with maghemite NPs by in situ synthesis. XRD, High-resolution transmission electron microscopy (HRTEM), Raman, and Mössbauer spectroscopy data revealed that the INPs exhibited the maghemite $\gamma-\mathrm{Fe}_{2} \mathrm{O}_{3}$ crystal structure. Transmission electron microscopy (TEM) images showed that the average diameter of the capsules was about $6.7 \mu \mathrm{m}$, while the average thickness of the capsule shell was $0.9 \mu \mathrm{m}$. The maghemite NPs in the capsule shell were rather monodisperse with a medium size of $7.5 \mathrm{~nm}$, indicating a unique and efficient mechanism of microcapsule formation. The most significant results obtained, from Mössbauer spectroscopy, however, were that approximately $80 \%$ of all the maghemite NPs with a diameter between 7 and $9 \mathrm{~nm}$ showed a marked superparamagnetic behavior which was retained up to room temperature due to slow spin relaxation. This means that the microcapsules can be directed to a predetermined site by generating a magnetic field of a permanent magnet. In addition, the porous nature of the core and the dissolution of $\mathrm{CaCO}_{3}$ after the layer-by-layer coating means that molecules trapped within the microcapsule can be absorbed. The mild conditions under which the MNPs incorporated in the microcapsules are synthesized may enable the encapsulation of bioactive substances without reducing their biological activity. Moreover, the characteristics of the microcapsules obtained means that they can be applied to the administration of drugs, in particular treatment by hyperthermia.

Zhou et al. [4] showed that thermoplastic magnetic bionanocomposites can be prepared from biocompatible dextran fatty acid esters and magnetite NPs with a melting point slightly above human body temperature. The heating response of the bionanocomposites to a high frequency AMF correlated with the content of the magnetite NPs and geometry of the sample. An optimal content of magnetite NPs between 1 and $2 \mathrm{wt} . \%$ and at least $50 \mu \mathrm{m}$ thick enabled the heating of samples to above the melting point. These results suggest that a controlled release system triggered by remote magnetic heating is possible.
Advantages of this approach compared to conventional methods include a reduced risk of leakage and a fast response.

According to Zhu et al. [3] one way to increase the efficacy whilst reducing the toxicity of antitumor drugs is to deliver the drug directly to the target site and maintain its concentration at that site for a sufficiently long therapeutic time. Recent strategies used to increase drug accumulation in a solid target tumor also include the use of hydrogels prepared from biopolymers. The widespread application of hydrogels in the biomedical field is largely due to their hydrated environment and tunable properties, which are similar to the native extracellular matrix. In situ forming systems are administered as aqueous solutions, but become gels under physiological conditions. Such behavior means that the hydrogels can be easily injected and their use is most suited for localized and minimally invasive drug delivery, where the sustained release of the drug is required. Thermosensitive hydrogels derived from CS and $\beta$-glycerophosphate are promising candidates, as they are biodegradable, biocompatible, nontoxic, and noninflammatory. However, challenges to the application of hydrogels still exist, such as their poor controllability, actuation, and response properties in drug delivery. Recently, however, magnetic hydrogels have emerged as potentially useful biocomposites due to their superparamagnetic and responsive properties.

Miyazaki et al. [12] developed carboxymethyldexran$\mathrm{Fe}_{3} \mathrm{O}_{4}$ composites using emulsions in order to prepare sol-gel microspheres for thermoseeding. Microspheres were obtained by dehydrating the sol in a water-in-oil emulsion. Sol-gel silica coatings were then prepared using different catalysts for hydrolysis and polycondensation, as under aqueous conditions the microspheres released a large number of iron ions. The silica coating prepared using an acidic catalyst effectively improved chemical durability under a simulated body environment, whereas the coating prepared using a basic catalyst did not. Numerous spherical NPs were observed on the microspheres prepared using the basic catalyst suggesting that the silica NPs formed on the carboxymethyldexran- $\mathrm{Fe}_{3} \mathrm{O}_{4}$ microspheres do not act as a continuous protective layer.

\subsection{BIOCOMPOSITES FROM IRON NANOPARTICLES-HYDROXYAPATITE}

In the biomaterial sciences, the development of new materials for the effective repair of bones is an important objective. Bone is itself a composite material made up of $60 \%-70 \%$ inorganic mineral crystal, the major component being HA in the form of tiny elongated crystals, and $30 \%-40 \%$ organic matrix, consisting mostly of collagen protein fibers $[139,140]$. HA, chemical formula 
$\mathrm{Ca}_{10}\left(\mathrm{PO}_{4}\right)_{6}(\mathrm{OH})_{2}$, has been extensively used for hard tissue replacement and augmentation due to its biocompatibility and osteoconductive potential [141]. However, this material is difficult to shape into the specific forms required for bone substitution due to its hardness and brittleness. Combining biopolymers with minerals to give biomaterials with the toughness and flexibility of the biopolymer component and the strength and hardness of the mineral filler has its origin in nature, for example, snail and crab shells. Inspired by this, composites of HA and bioorganic polymers that mimic these natural combinations have ignited great interest [142].

Currently, HA has attracted much attention due to the prospects for its use in the hyperthermic treatment of cancer [143]. To this end, a number of synthetic biocompatible magnetic composites made from HA and magnetic fillers have been developed, for example, spinel ferrites [144,145], metallic iron [146], and hexagonal ferrites [147].

Markak and Clyne [148] showed that magnetomechanical effects could stimulate bone growth in a bonded array of ferromagnetic fibers. Takegami et al. [149] prepared ferromagnetic bone cement by blending magnetite and silica glass powders with resin that could be used for local hyperthermia treatment in the skeletal system. The healing of bone fractures by magnetic therapy was studied by Baibekov and Khanapiyaev [150]. The preparation and application of magnetic polymer composites for biomedical applications are of great interest [51], however, these composites should be biocompatible, nontoxic, and biodegradable.

Keshri et al. [151] reported the synthesis pathway and some of the basic properties of a LSMO manganite-based biocomposite made from LSMO NPs mixed with HA NPs in order to ensure their biocompatibility. XRD and FTIR results confirmed the coexistence of both phases. DC magnetization measurements demonstrated that the LSMO-HA composite exhibited magnetic behavior similar to that of LSMO alone. However, mixing produced a decrease in the $T_{C}$ and magnetization values. Irreversibility in the temperature-dependent DC magnetization was also determined by ZFC and FC curves. The results of the magnetic hysteresis loop analysis demonstrated that the admixture of HA preserved the magnetic behavior of the parent sample, but with slightly lower saturation field, coercive field, and magnetic moment values. TEM results revealed that within the HA-LSMO composite, the LSMO NPs are surrounded by HA particles $300-600 \mathrm{~nm}$ wide. Particles of this size might prove advantageous for in vivo drug delivery systems. However, further research is needed in order to ensure the uniform coating of HA around the manganite NPs.

Tkachenko and Kamzin [2] developed a method for the synthesis of hybrid $\mathrm{HA}$-ferrite $\left(\mathrm{Fe}_{3} \mathrm{O}_{4}\right.$-based magnetic filler) ceramics with higher magnetization values than previously reported in the literature. These authors also investigated the structure of the synthesized hybrid ceramics, and the behavior of these materials in an external magnetic field. Carbonated HA-ferrite composite particles were synthesized using a two-stage procedure. The first stage involved the synthesis of ferrite particles by coprecipitation from $\mathrm{FeCl}_{2}$ and $\mathrm{FeCl}_{3}$ aqueous solutions, and the synthesis of carbonated HA. Mössbauer spectroscopy revealed that the ferrite particles obtained consisted of magnetite $\left(\mathrm{Fe}_{3} \mathrm{O}_{4}\right)$ and maghemite $\left(\gamma-\mathrm{Fe}_{2} \mathrm{O}_{3}\right)$. In the second stage carbonated HA-ferrite composite particles were synthesized by mixing the ferrite, $\mathrm{CaCO}_{3}$, and $\mathrm{H}_{3} \mathrm{PO}_{4}$ particles, followed by annealing at $1200^{\circ} \mathrm{C}$. The formation of the $\mathrm{HA}-$ ferrite composite was confirmed by XRD, analyzing the composition of the biocomposite, and measuring the magnetic properties. The saturation magnetizations of the ferrite components in the HA-ferrite composites were 46.4 and $48.0 \mathrm{emu} / \mathrm{g}$ for $\gamma-\mathrm{Fe}_{2} \mathrm{O}_{3}$ and $\mathrm{Fe}_{3} \mathrm{O}_{4}$, respectively.

CS, poly- $\beta(1,4)-2$-amino-2-deoxy-D-glucose, is a partly deacetylated product of chitin, which can be extracted from crustaceans and insects. Cui et al. [18] prepared novel superparamagnetic nanocomposites with various $\mathrm{Fe}_{3} \mathrm{O}_{4} / \mathrm{HA} / \mathrm{CS}$ ratios using the in situ compositing method. The use of these nanocomposites to provide temporary mechanical support for the regeneration of bone cell ingrowth in orthopedic applications was proposed owing to their biocompatiblity, nontoxicity, biodegradablity, and inherent wound healing characteristics [152]. In recent years, the combination of CS with biominerals to produce versatile biomaterials has attracted increasing interest [153]. A critical obstacle in assembling and maintaining nanoscaled materials from NP clusters is the tendency of the latter to aggregate, thus reducing the energy associated with a high surface area to volume ratio. Cui et al. [18] found that $\mathrm{Fe}_{3} \mathrm{O}_{4}$ and HA NPs with maximum sizes under $50 \mathrm{~nm}$ dispersed homogeneously in the nanocomposites they prepared, and that chemical bonds between the inorganic materials and CS molecules were formed.

Another method employed to treat oncological diseases is the magnetic hyperthermia of malignant bone tumors. This procedure uses thermo seeds from composite materials in a bioactive matrix (bioglass or ceramics based on calcium phosphate) and ferrimagnetic nano- and microparticles [154]. Brushite $\left(\mathrm{CaHPO}_{4} \cdot 2 \mathrm{H}_{2} \mathrm{O}\right)$-forming calcium phosphate bone cements have the advantage of being reabsorbable, whereas HA-forming cements are not, but suffer from their fast, water-consuming setting reaction, and low mechanical strength [5].

Matsumine et al. [155] proposed a $\mathrm{Fe}_{3} \mathrm{O}_{4}$-containing, calcium phosphate-based cement for the hyperthermic treatment of metastatic bone tumors in the femur, fibula, 
humerus, and tibia of human patients. Clinical trials were conducted with 15 patients that had suffered metastatic bone lesions (HT group). The results were then compared with those for 8 patients treated by a palliative operation (Op group), and 22 patients treated by an operation plus radiotherapy (Op + RT group). The patients in the HT group showed better radiographic outcomes than those in the Op group and no significant differences from those in the $\mathrm{Op}+\mathrm{RT}$ group. Nevertheless, although the $\mathrm{Fe}_{3} \mathrm{O}_{4^{-}}$ containing calcium phosphate-based cement was found to be useful for the hyperthermic treatment of these metastatic bone tumors, its mechanical strength is generally lower than that of polymethyl methacrylate (PMMA)based cement, and consequently is not ideal for the hyperthermic treatment of bone tumors subjected to a high load. To overcome this, the use of PMMA cement containing $\mathrm{Fe}_{3} \mathrm{O}_{4}$ NPs has recently been proposed $[12,156,157]$.

Beherei et al. [5] developed a nanobrushite filler powder which was then mixed with a $\gamma-\mathrm{Fe}_{2} \mathrm{O}_{3}$ powder and loaded onto a polymeric scaffold in order to improve its bioactivity, biodegradability, mechanical properties, and anticancer effects. The prepared biocomposites were then characterized in order to evaluate the homogeneity between the two matrices, and in vitro tests were performed to verify the formation of the apatite layer on the surface of the materials. The authors obtained a multifunctional scaffold material with bone regeneration and anticancer properties. The results from the in vitro tests showed that the concentrations of the $\mathrm{Ca}$ and $\mathrm{P}$ ions were inversely proportional to that of $\mathrm{Fe}_{2} \mathrm{O}_{3}$. Scaffold materials with $5 \% \gamma-\mathrm{Fe}_{2} \mathrm{O}_{3}$ did not produce the hyperthermic conditions required for effective treatment. However, scaffolds with a higher content of the composite (for example $10 \%$ and $15 \%$ ) could be successfully used to generate hyperthermia, with activation times of about $20-30$ minutes (at $150 \mathrm{kHz}$ ).

\subsection{CONCLUSIONS}

Treatment with hyperthermia based on the magnetic behavior of biocomposites, mainly INPs, has been successfully used in the fight against cancer. This technology has made it possible to reduce the side effects of conventional treatments such as chemotherapy, as it enables the site-specific delivery of the anticancer drugs. Hyperthermic treatment procedures still need to be improved, however, in order to overcome problems related to the surface characteristics and size of the biocomposites employed which may cause undesirable physiological reactions. Advances in the preparation methods of these biocomposites, as well as the coatings used and the characteristics of the cancer will determine their effectiveness for hyperthermia applications in the future. This chapter sought to gather recent information on the subject in order to promote further research in this scientific field. Specifically, aspects related to INP-biopolymers and INP-HAs were discussed.

\section{ACKNOWLEDGMENTS}

The authors would like to thank Consejo Nacional de Investigaciones Científicas y Técnicas (CONICET) (Postdoctoral fellowship internal PDTS-Resolution 2417) and Universidad Nacional de Mar del Plata (UNMdP) for the financial support, and Dr. Mirian Carmona-Rodríguez.

\section{REFERENCES}

[1] R.K. Gilchrist, R. Medal, W.D. Shorey, R.C. Hanselman, J.C. Parrott, C.B Taylor, Selective inductive heating of lymph nodes, Ann. Surg. 146 (4) (1957) 596.

[2] M.V. Tkachenko, A.S. Kamzin, Synthesis and properties of hybrid hydroxyapatite-ferrite $\left(\mathrm{Fe}_{3} \mathrm{O}_{4}\right)$ particles for hyperthermia applications, Phys. Solid State 58 (4) (2016) 763-770.

[3] X. Zhu, H. Zhang, H. Huang, Y. Zhang, L. Hou, Z. Zhang, Functionalized graphene oxide-based thermosensitive hydrogel for magnetic hyperthermia therapy on tumors, Nanotechnology 26 (36) (2015) 365103.

[4] M. Zhou, T. Liebert, R. Müller, A. Dellith, C. Gräfe, J.H. Clement, et al., Magnetic biocomposites for remote melting, Biomacromolecules 16 (8) (2015) 2308-2315.

[5] H.H. Beherei, M.S. Abdel-Aal, A.A. Shaltout, A. El-Magharby, Biophysiochemical characterization of anticancer nano-ceramic polymer scaffold for bone grafting, Pharm. Chem. 4 (1) (2012) 544-551.

[6] I. Safarik, K. Horska, M. Safarikova, Magnetically responsive biocomposites for inorganic and organic xenobiotics removal, Microbial Biosorption of Metals., Springer, Netherlands, 2011, pp. 301-320.

[7] P. Moroz, S.K. Jones, B.N. Gray, Status of hyperthermia in the treatment of advanced liver cancer, J. Surg. Oncol. 77 (4) (2001) 259-269.

[8] T. Kobayashi, Cancer hyperthermia using magnetic nanoparticles, Biotechnol. J. 6 (11) (2011) 1342-1347.

[9] J.P. Novoselova, A.P. Safronov, O.M. Samatov, I.V. Beketov, H. Khurshid, Z. Nemati, et al., Laser target evaporation $\mathrm{Fe}_{2} \mathrm{O}_{3}$ nanoparticles for waterbased ferrofluids for biomedical applications, IEEE Magn. 50 (11) (2014) $1-4$

[10] S. Mornet, S. Vasseur, F. Grasset, E. Duguet, Magnetic nanoparticle design for medical diagnosis and therapy, J. Mater. Chem. 14 (14) (2004) $2161-2175$.

[11] D.L. Thorek, A.K. Chen, J. Czupryna, A. Tsourkas, Superparamagnetic iron oxide nanoparticle probes for molecular imaging, Ann. Biomed. Eng. 34 (1) (2006) 23-38.

[12] T. Miyazaki, M. Kawashita, C. Ohtsuki, Ceramic-polymer composites for biomedical applications, in: I. Antoniac (Ed.), Handbook of Bioceramics and Biocomposites, Springer, Cham, 2016, pp. 287-300.

[13] J. Klostergaard, C.E. Seeney, Magnetic nanovectors for drug delivery, Nanomedicine 1 (2012) 37-50.

[14] C. Saviuc, A.M. Grumezescu, A. Holban, C. Bleotu, C. Chifiriuc, P. Balaure, et al., Phenotypical studies of raw and nanosystem embedded Eugenia carryophyllata buds essential oil antibacterial activity on Pseudomonas aeruginosa and Staphylococcus aureus strains, Biointerface Res. Appl. Chem. 1 (3) (2011) 111-118.

[15] A.M. Grumezescu, E. Ilinca, C. Chifiriuc, D. Mihaiescu, P. Balaure, V. Traistaru, et al., Influence of magnetic MWCNTs on the antimicrobial activity of cephalosporins, Biointerface Res. Appl. Chem. 1 (4) (2011) 139-144.

[16] F. Heidari, M.E. Bahrololoom, D. Vashaee, L. Tayebi, In situ preparation of iron oxide nanoparticles in natural hydroxyapatite/chitosan matrix for bone tissue engineering application, Ceram. Int. 41 (2) (2015) 3094-3100.

[17] M. Kawashita, M. Tanaka, T. Kokubo, Y. Inoue, T. Yao, S. Hamada, et al., Preparation of ferrimagnetic magnetite microspheres for in situ hyperthermic treatment of cancer, Biomaterials 26 (2005) 2231-2238. 
[18] W. Cui, Q. Hu, J. Wu, B. Li, J. Shen, Preparation and characterization of magnetite/hydroxyapatite/chitosan nanocomposite by in situ compositing method, J. Appl. Polym. Sci. 109 (4) (2008) 2081-2088.

[19] I.V. Beketov, A.P. Safronov, A.I. Medvedev, J. Alonso, G.V. Kurlyandskaya, S.M. Bhagat, Iron oxide nanoparticles fabricated by electric explosion of wire: focus on magnetic nanofluids, AIP Adv. 2 (2) (2012) 022154.

[20] A. Kumar, S. Mohapatra, V. Fal-Miyar, A. Cerdeira, J.A. Garcia, H. Srikanth, et al., Magnetoimpedance biosensor for $\mathrm{Fe}_{3} \mathrm{O}_{4}$ nanoparticle intracellular uptake evaluation, Appl. Phys. Lett. 91 (14) (2007) 143902-1-143902-3.

[21] C. Saviuc, A.M. Grumezescu, A. Holban, C. Chifiriuc, D. Mihaiescu, V. Lazar, Hybrid nanostructurated material for biomedical applications, Biointerface Res. Appl. Chem. 1 (2) (2011) 064-071.

[22] J. Zhao, H. Sekikawa, T. Kawai, H. Unuma, Ferrimagnetic magnetite hollow microspheres prepared via enzimatically precipitated iron hydroxide on a urease-bearing polymer template, J. Ceram. Soc. Jpn. 117 (2009) 344-346.

[23] T. Miyazaki, A. Miyaoka, E. Ishida, Z. Li, M. Kawashita, M. Hiraoka, Preparation of ferromagnetic microcapsules for hyperthermia using water/oil emulsion as a reaction field, Mater. Sci. Eng. C 32 (2012) 692-696.

[24] Y. Wang, B. Li, Y. Zhou, D. Jia, Chitosan-induced synthesis of magnetite nanoparticles via iron ions assembly, Polym. Adv. Technol. 19 (2008) $1256-1261$.

[25] M.A. Willard, L.K. Kurihara, E.E. Carpenter, S. Calvin, V.G. Harris, Chemically prepared magnetic nanoparticles, Int. Mater. Rev. 49 (2004) 125.

[26] Z.Y. Ma, Y.P. Guan, X.Q. Liu, H.Z. Liu, Covalent immobilization of albumin on micron-sized magnetic poly(methyl methacrylatedivinylbenzene-glycidyl methacrylate) microspheres prepared by modified suspension polymerization, Polym. Adv. Technol. 16 (2005) 554-558.

[27] M. Colombo, S. Carregal-Romero, M.F. Casula, L. Gutiérrez, M.P. Morales, I.B. Böhm, et al., Biological applications of magnetic nanoparticles, Chem. Soc. Rev. 41 (11) (2012) 4306-4334.

[28] C. Alexiou, W. Arnold, R.J. Klein, F.G. Parak, P. Hulin, C. Bergemann, et al., Locoregional cancer treatment with magnetic drug targeting, Cancer Res. 60 (2000) 6641-6648.

[29] H. Maeda, J. Wu, T. Sawa, Y. Matsumura, K. Hori, Tumor vascular permeability and the EPR effect in macromolecular therapeutics: a review, J. Control. Release 65 (2000) 271-284.

[30] X. Yang, L. Chen, B. Han, X. Yang, H. Duan, Preparation of magnetite and tumor dual-targeting hollow polymer microspheres with $\mathrm{pH}$-sensitivity for anticancer drug-carriers, Polymer 51 (12) (2010) 2533-2539.

[31] J.R. McCarthy, R. Weissleder, Multifunctional magnetic nanoparticles for targeted imaging and therapy, Adv. Drug. Delivery Rev. 60 (11) (2008) $1241-1251$.

[32] S. Dandamudi, R.B. Campbell, The drug loading, cytotoxicty and tumor vascular targeting characteristics of magnetite in magnetic drug targeting, Biomaterials 28 (31) (2007) 4673-4683.

[33] W. Zheng, F. Gao, H. Gu, Magnetic polymer nanospheres with high and uniform magnetite content, J. Magn. Magn. Mater. 288 (2005) 403-410.

[34] M.C. Chifiriuc, A.M. Grumezescu, C. Saviuc, C. Croitoru, D.E. Mihaiescu, V. Lazar, Improved antibacterial activity of cephalosporins loaded in magnetic chitosan microspheres, Int. J. Pharm. 436 (1-2) (2012) 201-205.

[35] A.M. Grumezescu, E. Andronescu, A. Ficai, C. Bleotu, D.E. Mihaiescu, M. C. Chifiriuc, Synthesis, characterization and in vitro assessment of the magnetic chitosan-carboxymethylcellulose biocomposite interactions with the prokaryotic and eukaryotic cells, Int. J. Pharm. 43 (2012) 771-777.

[36] G. Voicu, E. Andronescu, A.M. Grumezescu, K.S. Huang, A. Ficai, C.H. Yang, et al., Antitumor activity of magnetite nanoparticles: Influence of hydrocarbonated chain of saturated aliphatic monocarboxylic acids, Curr. Org. Chem. 17 (8) (2013) 831-840.

[37] A.G. Roca, M.P. Morales, K. O'Grady, C.J. Serna, Structural and magnetic properties of uniform magnetite nanoparticles prepared by high temperature decomposition of organic precursors, Nanotechnology 17 (11) (2006) 2783-2788.

[38] J. Wan, X. Chen, Z. Wang, X. Yang, Y. Qian, A soft-template-assisted hydrothermal approach to single-crystal $\mathrm{Fe}_{3} \mathrm{O}_{4}$ nanorods, J. Cryst. Growth 276 (3) (2005) 571-576.

[39] J. Xu, H. Yang, W. Fu, K. Du, Y. Sui, J. Chen, et al., Preparation and magnetic properties of magnetite nanoparticles by sol-gel method, J. Magn. Magn. Mater. 309 (2) (2007) 307-311.

[40] C. Albornoz, S.E. Jacobo, Preparation of a biocompatible magnetoc film from an aqueous ferrofluid, J. Magn. Magn. Mater. 305 (1) (2006) 12-15.
[41] A.B. Chin, I.I. Yaacob, Synthesis and characterization of magnetic iron oxide nanoparticles via w/o microemulsion and Massart's procedure, J. Mater. Process. Technol. 191 (1) (2007) 235-237.

[42] E.H. Kim, H.S. Lee, B.K. Kwak, B.K. Kim, Synthesis of ferrofluid with magnetic nanoparticles by sonochemical method for MRI contrast agent, J. Magn. Magn. Mater. 289 (2005) 328-330.

[43] G.S. Alvarez, M. Muhammed, A.A. Zagorodni, Novel flow injection synthesis of iron oxide nanoparticles with narrow size distribution, Chem. Eng. Sci. 61 (14) (2006) 4625-4633.

[44] M. Kimata, D. Nakagawa, M. Hasegawa, Preparation of monodisperse magnetic particles by hydrolysis of iron alkoxide, Powder Technol. 132 (2) (2003) 112-118.

[45] S. Basak, D.-R. Chen, P. Biswas, Electrospray of ionic precursor solutions to synthesize iron oxide nanoparticles: modified scaling law, Chem. Eng. Sci. 62 (4) (2007) 1263-1268.

[46] B. Tural, N. Ozkan, M. Volkan, Preparation and characterization of polymer coated superparamagnetic magnetite nanoparticle agglomerates, J. Phys. Chem. Solids 70 (5) (2009) 860-866.

[47] A.P.A. Faiyas, E.M. Vinod, J. Joseph, R. Ganesan, R.K. Pandey, Dependence of $\mathrm{pH}$ and surfactant effect in the synthesis of magnetite $\left(\mathrm{Fe}_{3} \mathrm{O}_{4}\right)$ nanoparticles and its properties, J. Magn. Magn. Mater. 322 (4) (2010) 400-404.

[48] T.K. Jain, M.A. Morales, S.K. Sahoo, D.L. Leslie, V. Labhasetwar, Iron oxide nanoparticles for sustained delivery of anticancer agents, Mol. Pharm. 2 (3) (2005) 194-205.

[49] J. Sun, S. Zhou, P. Hou, Y. Yang, J. Weng, X. Li, et al., Synthesis and characterization of biocompatible $\mathrm{Fe}_{3} \mathrm{O}_{4}$ nanoparticles, J. Biomed. Mater. Res. Part A 80 (2) (2007) 333-341.

[50] I.N. Kosa, A. Recnik, M. Posfai, Novel methods for the synthesis of magnetite nanoparticles with special morphologies and textured assemblages, J. Nanopart. Res. 14 (10) (2012) 1150-1160.

[51] A.K. Gupta, M. Gupta, Synthesis and surface engineering of iron oxide nanoparticles for biomedical applications, Biomaterials 26 (18) (2005) 3995-4021.

[52] C. Bergemann, D. Müller-Schulte, J.A. Oster, L.à Brassard, A.S. Lübbe, Magnetic ion-exchange nano-and microparticles for medical, biochemical and molecular biological applications, J. Magn. Magn. Mater. 194 (1) (1999) 45-52.

[53] M.A. López-Quintela, J. Rivas, Chemical reactions in microemulsions: a powerful method to obtain ultrafine particles, J. Colloid Interface Sci. 158 (2) (1993) 446-451.

[54] N. Feltin, M.P. Pileni, New technique for synthesizing iron ferrite magnetic nanosized particles, Langmuir 13 (15) (1997) 3927-3933.

[55] F.A. Tourinho, R. Franck, R. Massart, Aqueous ferrofluids based on manganese and cobalt ferrites, J. Mater. Sci. 25 (7) (1990) 3249-3254.

[56] S. Ge, X. Shi, K. Sun, C. Li, C. Uher, Baker Jr, et al., Facile hydrothermal synthesis of iron oxide nanoparticles with tunable magnetic properties, J. Phys. Chem. C 113 (31) (2009) 13593-13599.

[57] J.F. Hochepied, M.P. Pileni, Magnetic properties of mixed cobalt-zinc ferrite nanoparticles, J. Appl. Phys. 87 (5) (2000) 2472-2478.

[58] M. Niederberger, F. Krumeich, K. Hegetschweiler, R. Nesper, An iron polyolate complex as a precursor for the controlled synthesis of monodispersed iron oxide colloids, Chem. Mater. 14 (1) (2002) 78-82.

[59] M. Wu, Y. Xiong, Y. Jia, H. Niu, H. Qi, J. Ye, et al., Magnetic fieldassisted hydrothermal growth of chain-like nanostructure of magnetite, Chem. Phy. Lett. 401 (4) (2005) 374-379.

[60] Z.J. Zhang, X.Y. Chen, B.N. Wang, C.W. Shi, Hydrothermal synthesis and self-assembly of magnetite $\left(\mathrm{Fe}_{3} \mathrm{O}_{4}\right)$ nanoparticles with the magnetic and electrochemical properties, J. Cryst. Growth 310 (24) (2008) 5453-5457.

[61] F. Chen, Q. Gao, G. Hong, J. Ni, Synthesis and characterization of magnetite dodecahedron nanostructure by hydrothermal method, J. Magn. Magn. Mater. 320 (11) (2008) 1775-1780.

[62] C.Y. Haw, F. Mohamed, C.H. Chia, S. Radiman, S. Zakaria, N.M. Huang, et al., Hydrothermal synthesis of magnetite nanoparticles as MRI contrast agents, Ceram. Int. 36 (4) (2010) 1417-1422.

[63] J. Liang, L. Li, M. Luo, J. Fang, Y. Hu, Synthesis and properties of magnetite $\mathrm{Fe}_{3} \mathrm{O}_{4}$ via a simple hydrothermal route, Solid State Sci. 12 (8) (2010) $1422-1425$

[64] M.T. Liang, S.H. Wang, Y.L. Chang, H.I. Hsiang, H.J. Huang, M.H. Tsai, et al., Iron oxide synthesis using a continuous hydrothermal and solvothermal system, Ceram. Int. 36 (3) (2010) 1131-1135. 
[65] F. Márquez, T. Campo, M. Cotto, R. Polanco, R. Roque, P. Fierro, et al., Synthesis and characterization of monodisperse magnetite hollow microspheres, Soft Nanosci. Lett. 1 (2) (2011) 25-32.

[66] G. Tataru, M. Popa, J. Desbrieres, Magnetic microparticles based on natural polymers, Int. J. Pharm. 404 (1-2) (2011) 83-93.

[67] H. Wang, S. Wang, Z. Liao, P. Zhao, W. Su, R. Niu, et al., Folatetargeting magnetic core-shell nanocarriers for selective drug release and imaging, Int. J. Pharm. 430 (1) (2011) 342-349.

[68] C. Fan, W. Gao, Z. Chen, H. Fan, M. Li, F. Deng, et al., Tumor selectivity of stealth multi-functionalized superparamagnetic iron oxide nanoparticles, Int. J. Pharm. 404 (1-2) (2011) 180-190

[69] S.S. Aleksenko, A.Y. Shmykov, S. Oszwałdowski, A.R. Timerbaev, Interactions of tumour-targeting nanoparticles with proteins: potential of using capillary electrophoresis as a direct probe, Metallomics. 4 (11) (2012) 1141-1148.

[70] S. García-Jimeno, E. Escribano, J. Queralt, J. Estelrich, Magnetoliposomes prepared by reverse-phase followed by sequential extrusion: Characterization and possibilities in the treatment of inflammation, Int. J. Pharm. 405 (1-2) (2011) 181-187.

[71] E. Alphandéry, F. Guyot, I. Chebbi, Preparation of chains of magnetosomes, isolated from magnetospirillum magneticum strain AMB-1 magnetotactic bacteria, yielding efficient treatment of tumors using magnetic hyperthermia, Int. J. Pharm. 434 (1-2) (2012) 444-452.

[72] M.D. Mantle, Quantitative magnetic resonance micro-imaging methods for pharmaceutical research, Int. J. Pharm. 417 (1) (2011) 173-195.

[73] A.M. Grumezescu, C. Saviuc, A. Holban, R. Hristu, C. Croitoru, G. Stanciu, et al., Magnetic chitosan for drug targeting and in vitro drug delivery response, Biointerface Res. Appl. Chem. 1 (5) (2011) 160-165.

[74] D.E. Mihaiescu, A.M. Grumezescu, P.C. Balaure, D.E. Mogosanu, V. Traistaru, Magnetic scaffold for drug targeting: evaluation of cephalosporins controlled release profile, Biointerface Res. Appl. Chem. 1 (5) (2011) $191-195$.

[75] Y. Liu, B. Zhang, B. Yan, Enabling anticancer therapeutics by nanoparticle carriers: the delivery of paclitaxel, Int. J. Mol. Sci. 12 (7) (2011) 4395-4413

[76] D.E. Mihaiescu, A.M. Grumezescu, D.E. Mogosanu, V. Traistaru, P.C Balaure, A. Buteica, Hybrid organic/inorganic nanomaterial for controlled cephalosporins release, Biointerface Res. Appl. Chem. 1 (2) (2011) 41-47.

[77] M. Wang, M. Thanou, Targeting nanoparticles to cancer, Pharmacol. Res. 62 (2) (2010) 90-99.

[78] M.A. Phillips, M.L. Gran, N.A. Peppas, Targeted nanodelivery of drugs and diagnostics, Nano Today 5 (2) (2010) 143-159.

[79] N. Kawai, A. Ito, Y. Nakahara, M. Futakuchi, T. Shirai, H. Honda, et al., Anticancer effect of hyperthermia on prostate cancer mediated by magnetite cationic liposomes and immune-response induction in transplanted syngeneic rats, Prostate 64 (4) (2005) 373-381.

[80] M. Yanase, M. Shinkai, H. Honda, T. Wakabayashi, J. Yoshida, T. Kobayashi, Antitumor immunity induction by intracellular hyperthermia using magnetite cationic liposomes, Cancer Sci. 89 (7) (1998) 775-782.

[81] A. Ito, Y. Kuga, H. Honda, H. Kikkawa, A. Horiuchi, Y. Watanabe, et al., Magnetite nanoparticle-loaded anti-HER2 immunoliposomes for combination of antibody therapy with hyperthermia, Cancer Lett. 212 (2) (2004) $167-175$.

[82] Y. Masuko, K. Tazawa, H. Sato, E. Viroonchatapan, S. Takemori, T. Shimizu, et al., Antitumor activity of selective hyperthermia in tumorbearing rats using thermosensitive magnetoliposomes as a new hyperthermic material, Drug Delivery 4 (1) (1997) 37-42.

[83] F.X. Hu, K.G. Neoh, E.T. Kang, Synthesis and in vitro anti-cancer evaluation of tamoxifen-loaded magnetite/PLLA composite nanoparticles, Biomaterials 27 (33) (2006) 5725-5733

[84] B. Koppolu, Z. Bhavsar, A.S. Wadajkar, S. Nattama, M. Rahimi, F. Nwariaku, et al., Temperature-sensitive polymer-coated magnetic nanoparticles as a potential drug delivery system for targeted therapy of thyroid cancer, J. Biomed. Nanotechnol. 8 (6) (2012) 983-990.

[85] X.Y. Sun, W.Q. Liang, Comparison on antitumor activity of cisplatinloaded liposomes and nanoparticles in vitro, J. Zhejiang Univ. Med. Sci. 40 (4) (2011) 408-413.

[86] M.E. Gindy, R.K. Prud'homme, Multifunctional nanoparticles for imaging, delivery and targeting in cancer therapy, Expert Opin. Drug Delivery 6 (8) (2009) 865-878
[87] D. Paneva, N. Manolova, M. Argirova, I. Rashkov, Antibacterial electrospun poly(e-caprolactone)/ascorbyl palmitate nanofibrous materials, Int. J. Pharm. 416 (1) (2011) 346-355.

[88] P. Legrand, V. Rioux, The complex and important cellular and metabolic functions of saturated fatty acids, Lipids 45 (10) (2010) 941-946.

[89] D.A. Towler, J.I. Gordon, S.P. Adams, L. Glaser, The biology and enzymology of eukaryotic protein acylation, Annu. Rev. Biochem. 57 (1) (1988) 69-99

[90] D.A. Mitchell, A. Vasudevan, M.E. Linder, R.J. Deschenes, Protein palmitoylation by a family of DHHC protein S-acyltransferases, J. Lipid Res. 47 (6) (2006) 1118-1127.

[91] N. Sakurai, T. Utsumi, Posttranslational $N$-myristoylation is required for the anti-apoptotic activity of human tGelsolin, the C-terminal caspase cleavage product of human gelsolin, J. Biol. Chem. 281 (20) (2006) $14288-14295$.

[92] T. Utsumi, N. Sakurai, K. Nakano, R. Ishisaka, C-terminal 15 kDa fragment of cytoskeletal actin is posttranslationally N-myristoylated upon caspase-mediated cleavage and targeted to mitochondria, FEBS Lett. 539 $(1-3)(2003) 37-44$.

[93] G.L. Vilas, M.M. Corvi, G.J. Plummer, A.M. Seime, G.R. Lambkin, L.G. Berthiaume, Posttranslational myristoylation of caspase-activated p21-activated protein kinase 2 (PAK2) potentiates late apoptotic events, Proc. Natl. Acad. Sci. U.S.A. 103 (17) (2006) 6542-6547.

[94] J. Zha, S. Weiler, K.J. Oh, M.C. Wei, S.J. Korsmeyer, Posttranslational $N$ myristoylation of BID as a molecular switch for targeting mitochondria and apoptosis, Science 290 (5497) (2000) 1761-1765.

[95] S. Maurer-Stroh, M. Gouda, M. Novatchkova, A. Schleiffer, G. Schneider, F.L. Sirota, et al., MYRbase: analysis of genome-wide glycine myristoylation enlarges the functional spectrum of eukaryotic myristoylated proteins, Genome. Biol. 5 (3) (2004) 1-16.

[96] C.A. Chen, D.R. Manning, Regulation of G proteins by covalent modification, Oncogene 20 (13) (2001) 1643-1652.

[97] C. Xu, K. Chakravarty, X. Kong, T.T. Tuy, I.J. Arinze, F. Bone, et al., Several transcription factors are recruited to the glucose-6-phosphatase gene promoter in response to palmitate in rat hepatocytes and H4IIE cells, J. Nutr. 137 (3) (2007) 554-559.

[98] N. Budick-Harmelin, S. Anavi, Z. Madar, O. Tirosh, Fatty acids-stress attenuates gluconeogenesis induction and glucose production in primary hepatocytes, Lipids Health Dis. 9 (11) (2012) 66.

[99] J.Y. Lee, K.H. Sohn, S.H. Rhee, D. Hwang, Saturated fatty acids, but not unsaturated fatty acids, induce the expression of cyclooxygenase- 2 mediated through Toll-like receptor 4, J. Biol. Chem. 276 (20) (2001) $16683-16689$

[100] A. Rada-Iglesias, S. Enroth, A. Ameur, K.M. Koch, G.K. Clelland, P. Respuela-Alonso, et al., Butyrate mediates decrease of histone acetylation centered on transcription start sites and down-regulation of associated genes, Genome. Res. 17 (6) (2007) 708-719.

[101] J. Chen, F.M. Ghazawi, W. Bakkar, Q. Li, Valproic acid and butyrate induce apoptosis in human cancer cells through inhibition of gene expression of Akt/protein kinase B, Mol. Cancer 5 (1) (2006) 71.

[102] E. Beauchamp, X. Tekpli, G. Marteil, D. Lagadic-Gossmann, P. Legrand, V. Rioux, $N$-myristoylation targets dihydroceramide $\Delta 4$-desaturase 1 to mitochondria: partial involvement in the apoptotic effect of myristic acid, Biochimie. 91 (11) (2009) 1411-1419.

[103] K. Staiger, H. Staiger, C. Weigert, C. Haas, H.U. Haring, M. Kellerer, Saturated, but not unsaturated, fatty acids induce apoptosis of human coronary artery endothelial cells via nuclear factor- $\mathrm{kB}$ activation, Diabetes 55 (11) (2006) 3121-3126.

[104] M. Belakavadi, B.T. Prabhakar, B.P. Salimath, Purification and characterization of butyrate-induced protein phosphatase involved in apoptosis of Ehrlich ascites tumor cells, Biochim. Biophys. Acta 1770 (1) (2007) $39-47$

[105] M. Maeda, N. Scaglia, R.A. Igal, Regulation of fatty acid synthesis and $\Delta$ 9-desaturation in senescence of human fibroblasts, Life Sci. 84 (3) (2009) 119-124.

[106] J.H. Ford, Saturated fatty acid metabolism is key link between cell division, cancer, and senescence in cellular and whole organism aging, Age 32 (2) (2010) 231-237.

[107] H. Sampath, M. Miyazaki, A. Dobrzyn, J.M. Ntambi, Stearoyl-CoA desaturase-1 mediates the pro-lipogenic effects of dietary saturated fatty acids, J. Biol. Chem. 282 (4) (2007) 2483-2493. 
[108] J.E. Hunter, J. Zhang, P.M. Kris-Etherton, Cardiovascular disease risk of dietary stearic acid compared with trans, other saturated and unsaturated fatty acids: a systematic review, Am. J. Clin. Nutr. 91 (1) (2010) $46-63$.

[109] P. Legrand, D. Catheline, V. Rioux, G. Durand, Lauric acid is desaturated to $\mathrm{C} 12: 1 \mathrm{n}-3$ by rat liver homogenate and hepatocytes, Lipids 37 (6) (2002) $569-572$.

[110] M.Y. Hua, H.W. Yang, C.K. Chuang, R.Y. Tsai, W.J. Chen, K.L. Chuang, et al., Magnetic-nanoparticlemodified paclitaxel for targeted therapy for prostate cancer, Biomaterials 31 (28) (2010) 7355-7363.

[111] K.J. Tapan, A.M. Marco, K.S. Sanjeeb, L.L.P. Diandra, L. Vinod, Iron oxide nanoparticles for sustained delivery of anticancer agents, Mol. Pharm. 2 (3) (2005) 194-205.

[112] R.R. Sawant, O.S. Vaze, K. Rockwell, V.P. Torchilin, Palmitoyl ascorbatemodified liposomes as nanoparticle platform for ascorbate-mediated cytotoxicity and paclitaxel co-delivery, Eur. J. Pharm. Biopharm. 75 (3) (2010) $321-326$.

[113] J. Fang, T. Seki, H. Maeda, Therapeutic strategies by modulating oxygen stress in cancer and inflammation, Adv. Drug Delivery Rev. 61 (4) (2009) 290-302.

[114] M.F. McCarty, J. Barroso-Aranda, F. Contreras, Oxidative stress therapy for solid tumors - a proposal, Med. Hypotheses 74 (6) (2010) 1052-1054.

[115] S.P. Foy, V. Labhasetwar, Oh the irony: iron as a cancer cause or cure? Biomaterials 32 (35) (2011) 9155-9158.

[116] W. Mehnert, K. Mäder, Solid lipid nanoparticles: production, characterization and applications, Adv. Drug Delivery Rev. 47 (2) (2001) 165-196.

[117] R.H. Müller, K. Mäder, S. Gohla, Solid lipid nanoparticles (SLN) for controlled drug delivery - a review of the state of the art, Eur. J. Pharm. Biopharm. 50 (1) (2000) 161-177.

[118] A. Puri, K. Loomis, B. Smith, J.H. Lee, A. Yavlovich, E. Heldman, et al., Lipid-based nanoparticles as pharmaceutical drug carriers: from concepts to clinic, Crit. Rev. Ther. Drug Carrier Syst. 26 (6) (2009) 523-580.

[119] H.L. Wong, R. Bendayan, A.M. Rauth, Y. Li, X.Y. Wu, Chemotherapy with anticancer drugs encapsulated in solid lipid nanoparticles, Adv. Drug Delivery Rev. 59 (6) (2007) 491-504

[120] P. Tartaj, M. del Puerto Morales, S. Veintemillas-Verdaguer, T. GonzalezCarreno, C.J. Serna, The preparation of magnetic nanoparticles for applications in biomedicine, J. Phys. D Appl. Phys. 36 (13) (2003) R182.

[121] A.K. Gupta, S. Wells, Surface superparamagnetic nanoparticles for drug delivery: preparation, characterization, and cytotoxicity studies, IEEE Trans. Nanobiosci. 3 (1) (2004) 66-73.

[122] E.B. Denkbaş, E. Kiliçay, C. Birlikseven, E. Öztürk, Magnetic chitosan microspheres: preparation and characterization, React. Funct. Polym. 50 (3) (2002) 225-232

[123] C.C. Berry, A.S.G. Curtis, Functionalisation of magnetic nanoparticles for applications in biomedicine, J. Phys. D Appl. Phys. 36 (13) (2003) R198-R206.

[124] S.S.R. Kumar, C.F. Mohammad, Magnetic nanomaterials for hyperthermia-based therapy and controlled drug delivery, Adv. Drug Delivery Rev. 63 (9) (2011) 789-808.

[125] J. Li, Y. Qu, J. Ren, W. Yuan, D. Shi, Magnetocaloric effect in magnetothermally responsive nanocarriers for hyperthermiatriggered drug release, Nanotechnology 23 (50) (2012) 505706.

[126] M.S. Yavuz, Y. Cheng, J. Chen, C.M. Cobley, Q. Zhang, M. Rycenga, et al., Gold nanocages covered by smart polymers for controlled release with near-infrared light, Nat. Mater. 8 (12) (2009) 935-939.

[127] M. Soleymani, M. Edrissi, M.A. Alizadeh, Thermosensitive polymercoated $\mathrm{La}_{0.73} \mathrm{Sr}_{0.27} \mathrm{MnO}_{3}$ nanoparticles: potential applications in cancer hyperthermia therapy and magnetically activated drug delivery systems, Polym. J. 47 (2015) 797-801.

[128] K.R. Bhayani, S.N. Kale, S. Arora, R. Rajagopal, H. Mamgain, R. Kaul-Ghanekar, et al., Protein and polymer immobilized nanoparticles for possible biomedical applications, Nanotechnology 18 (34) (2007) 345108.

[129] S. Biswas, S. Keshri, S. Goswami, J. Isaac, S. Ganguly, N. Perov, Antibiotic loading and release studies of LSMO nanoparticles embedded in an acrylic polymer, Phase Transitions 89 (2) (2016) 1203-1212.

[130] R. Gupta, A.K.J. Bajpai, Magnetically guided release of ciprofloxacin from superparamagnetic polymer nanocomposites, J. Biomater. Sci., Polym. Ed. 22 (2011) 893-918.
[131] R. Weissleder, A. Bogdanov, E.A. Neuwelt, M. Papisov, Long-circulating iron oxides for MR imaging, Adv. Drug Delivery Rev. 16 (2) (1995) $321-334$.

[132] T. Aziz, S.M. Masum, M.R. Qadir, A. Gafur, D. Huq, Physicochemical characterization of iron oxide nanoparticle coated with chitosan for biomedical application, Int. Res. J. Pure Appl. Chem. 1 (1) (2016) 1-9.

[133] S. Qu, H. Yang, D. Ren, S. Kan, G. Zou, D. Li, et al., Magnetite nanoparticles prepared by precipitation from partially reduced ferric chloride aqueous solutions, J. Colloid Interface Sci. 215 (1) (1999) 190-192.

[134] W. Tiaboonchai, N. Limpeanchob, Formulation and characterization of amphotericin B-chitosan-dextran sulfate nanoparticles, Int. J. Pharm. 329 (1) (2007) 142-149.

[135] S.A. Agnihotri, N.N. Mallikarjuna, T.M. Aminabhavi, Recent advances on chitosan-based micro and nanoparticles in drug delivery, J. Control. Release 100 (1) (2004) 5-28.

[136] J.H. Park, G. Saravanakumar, K. Kim, I.C. Kwon, Targeted delivery of low molecular drugs using chitosan and its derivatives, Adv. Drug Delivery Rev. 62 (1) (2010) 28-41.

[137] M.K. Kabiraj, I.A. Jahan, S.M. Masum, M.M. Islam, S.M.M. Hasan, B. Saha, et al., Effective removal of chromium (VI) ions from tannery effluent using chitosan-alumina composite, Int. Res. J. Pure Appl. Chem. 10 (3) (2015) $1-12$.

[138] I.S. Lyubutin, S.S. Starchikov, T.V. Bukreeva, I.A. Lysenko, S.N. Sulyanov, N.Y. Korotkov, et al., In situ synthesis and characterization of magnetic nanoparticles in shells of biodegradable polyelectrolyte microcapsules, Mater. Sci. Eng. C 45 (2014) 225-233.

[139] S. Ramesh, Grain size-properties correlation in polycrystalline hydroxyapatite bioceramic, Malays. J. Chem. 3 (1) (2001) 35-40.

[140] S.H. Rhee, Y. Suetsugu, J. Tanaka, Biomimetic configurational arrays of hydroxyapatite nanocrystals on bio-organics, Biomaterials 22 (21) (2001) 2843-2847.

[141] G. Saraswathy, S. Pal, C. Rose, T.P. Sastry, A novel bio-inorganic bone implant containing deglued bone, chitosan and gelatin. B, Mater. Sci. 24 (4) (2001) 415-420.

[142] A.C. Wan, E. Khor, G.W. Hastings, Hydroxyapatite modified chitin as potential hard tissue substitute material, J. Biomed. Mater. Res. 38 (3) (1997) 235-241.

[143] N. Roveri, M. Iafisco, Evolving application of biomimetic nanostructured hydroxyapatite, Nanotechnol. Sci. Appl. 3 (1) (2010) 107-125.

[144] W. Pon-On, S. Meejoo, I.M. Tang, Substitution of manganese and iron into hydroxyapatite: core/shell nanoparticles, Mater. Res. Bull. 43 (8) (2008) 2137-2144.

[145] A. Inukai, N. Sakamoto, H. Aono, O. Sakurai, K. Shinozaki, H. Suzuki, et al., Synthesis and hyperthermia property of hydroxyapatite-ferrite hybrid particles by ultrasonic spray pyrolysis, J. Magn. Magn. Mater. 323 (7) (2011) 965-969.

[146] W. Pon-On, S. Meejoo, I.M. Tang, Incorporation of iron into nano hydroxyapatite particles synthesized by the microwave process, Int. J. Nanosci. 6 (01) (2007) 9-16.

[147] M.V. Tkachenko, A.S. Kamzin, L.P. Ol'khovik, T.M. Tkachenko, S. Keshri, Synthesis and study of the new class of magnetic bioceramics for biomedical applications: mossbauer studies, Solid State Phenomena, Vol. 215, 2014, pp. 480-488.

[148] A.E. Markaki, T.W. Clyne, Magneto-mechanical stimulation of bone growth in a bonded array of ferromagnetic fibres, Biomaterials 25 (19) (2004) 4805-4815.

[149] K. Takegami, T. Sano, H. Wakabayashi, J. Sonoda, T. Yamazaki, S. Morita, et al., New ferromagnetic bone cement for local hyperthermia, J. Biomed. Mater. Res. 43 (2) (1998) 210-214.

[150] I.M. Baibekov, U.K. Khanapiyaev, Healing of bone fractures of rat shin and some immunological indices during magnetic laser therapy and osteosynthesis by the Ilizarov method., Bull. Exp. Biol. Med. 131 (4) (2001) 399-402.

[151] S. Keshri, V. Kumar, P. Wiśniewski, A.S. Kamzin, Synthesis and characterization of LSMO manganite-based biocomposites, Phase Transitions 87 (5) (2014) 468-476.

[152] M. Ito, Y. Hidaka, M. Nakajima, H. Yagasaki, A.H. Kafrawy, Effect of hydroxyapatite content on physical properties and connective tissue reactions to a chitosan-hydroxyapatite composite membrane, J. Biomed. Mater. Res. 45 (3) (1999) 204-208. 
576 PART | VI Engineered Nanomaterial in Biomedical and Pharmaceutical Industry

[153] C. Muzzarelli, R.A. Muzzarelli, Natural and artificial chitosan-inorganic composites, J. Inorg. Biochem. 92 (2) (2002) 89-94.

[154] M.V. Tkachenko, L.P. Ol'khovik, A.S. Kamzin, S. Keshri, Polyfunctional bioceramics based on calcium phosphate and M-type hexagonal ferrite for medical applications, Tech. Phys. Lett. 40 (1) (2014) 4-6.

[155] A. Matsumine, K. Kusuzaki, T. Matsubara, K. Shintani, H. Satonaka, T. Wakabayashi, et al., Novel hyperthermia for metastatic bone tumors with magnetic materials by generating an alternating electromagnetic field, Clin. Exp. Metastasis 24 (3) (2007) 191-200.
[156] M. Kawashita, K. Kawamura, Z. Li, PMMA-based bone cements containing magnetite particles for the hyperthermia of cancer, Acta Biomater. 6 (8) (2010) 3187-3192.

[157] Z. Li, K. Kawamura, M. Kawashita, T. Kudo, H. Kanetaka, M. Hiraoka, In vitro heating capability, mechanical strength and biocompatibility assessment of PMMA-based bone cement containing magnetite nanoparticles for hyperthermia of cancer, J. Biomed. Mater. Res. Part A 100 (10) (2012) $2537-2545$ 